\title{
Ranking Countries by Medal Priorities Won in the 2014 Sochi Winter Olympics
}

\author{
Thomas L. Saaty • Xiaoyue Liu • Michael Sanserino
}

Received: 3 April 2014 / Revised: 1 July 2014 / Accepted: 20 August 2014 /

Published online: 28 October 2014

(C) Springer-Verlag Berlin Heidelberg 2014

\begin{abstract}
The total number of gold, silver and bronze medals won by each country in the Olympics is often regarded as an indicator of that country's winning rank. However, the values of the medals differ according to the order in which they are won in each event. One reason why it is done this way is that there has not been a scientific way to assign an appropriate priority for each type of medal which so far has been treated as an intangible. Sometimes people have used the ordinal numbers 3, 2, 1 to rank the medals, but adding ordinals has no arithmetic legitimacy because ordinals cannot be added or multiplied. Here we use the mathematical theory, the analytic hierarchy process, for the measurement of intangibles to quantify the priorities of different games according to environmental and people factors and also quantify the priorities of gold, silver and bronze medals, and then use these priorities to compute the total scores of all three types of medals won by each country in order to determine the ranking of the countries which won medals in the 22nd Winter Olympics held February 07-23, 2014, in Sochi, Russia.
\end{abstract}

Keywords Sochi Winter Olympics · Game priority · Medal priority · Ranking countries · Analytic hierarchy process (AHP)

\footnotetext{
T. L. Saaty $(\varangle)$

University of Pittsburgh, Pittsburgh, PA 15260, USA

e-mail: saaty@katz.pitt.edu

X. Liu

Beijing Institute of Technology, Beijing 10081, China e-mail: sxy880530@163.com

M. Sanserino

Pittsburgh Post Dispatch, Pittsburgh, PA 15222, USA

e-mail: msanserino@post-gazette.com
} 


\section{Introduction}

The modern Olympic Games are a major international event featuring summer and winter sports in which thousands of athletes participate in a variety of competitions. They are considered to be the world's foremost sports competition with nearly 100 nations participating. The Games are currently held biennially, alternating between summer and winter Olympic. As we know, the 22nd Winter Olympics, officially known as the XXII Olympic Winter Games, was a major international multiple sport event held in Sochi, Russia, in the tradition of the Winter Olympic Games. It was held during February 7-23, 2014, with opening rounds in certain events held on the eve of the opening ceremony, February 6, 2014. In this Olympics, there were a total of 98 events in 7 games and 15 disciplines, which were held around two clusters of new venues: an Olympic Park constructed in Sochi's Imeretinsky Valley on the coast of the Black Sea at the Fisht Olympic Stadium. The indoor venue was located within a walking distance, and the snow events in the resort settlement of Krasnaya Polyana.

Generally, one does not think of countries winning the Olympics but simply of individuals winning medals. It is an interesting thought experiment in a global competitive world to ask the question: Which country is the winner of the Sochi Winter Olympics and what are the priority rankings of all the participating countries according to the medals they won? How do we decide that and what is the best way to do such ranking? This question has been explored by others in references [1-5]. In reality, one common but logically poor way used to solve this problem is to use the total number of medals won by each country. In addition, if two or more countries are tied in the total number of medals, the gold medals play a role in the ranking. If they are tied in gold medals, then the number of silver medals is used to break the tie. Finally, if they are tied in both gold and silver medals, the number of bronze medals is used to break the tie. If all medals of each kind for both countries are of equal, then something else has to be considered. This method implies that all medals gold, silver and bronze are considered as equally important. However, the value of a gold medal is different from the value of a silver medal and different from that of a bronze medal. To solve this issue, two methods were proposed. One method is to assign the values of 3, 2 and 1 respectively that are ordinal numbers to gold, silver and bronze medals. This method seems simple but arbitrary. Moreover, adding ordinals has no arithmetic legitimacy because ordinals cannot be added or multiplied. Another method of scoring medals has been proposed by dividing the games into two types of competition: high profile events to which higher numbers are assigned in weighting medals and low profile events which receive smaller numbers. The totals are obtained by summing the values of all medals won by each country to determine the ranking of all participating countries.

It is known that television networks broadcast favorite games to the relevant countries. Not only that, but preferences shift depending on whether countries happen to have an outstanding athlete in some other sport. Thus, if one were to determine the overall values of the gold, silver and bronze medals according to the emphasis people place on winning games their country specializes in, there would be no general agreement on an overall winner. To attempt prioritizing the values of medals won by 
weighting them by the priorities of the games in which they are won would be impossible because there would be no universal agreement among the countries about such priorities. It might be possible to arrive at a ranking of countries from the perspective of each country using its preferences, but there is no way to arrive at an agreed upon universal ranking if one starts taking subjective factors into account. One can conceivably use the relative amount of money a country spends on different games and events to rank the countries and thus obtain an overall ranking for all the countries. This is why instead of using a subjective and disparate kind of ranking in competition, an objective mathematical approach needs to be devised and adopted to get a universally accepted ranking of countries. In this paper we demonstrate in some detail how to look at the problem of ranking countries according to the medals won and the events in which they are won. Our methodology consists of the following steps:

(1) "Expert" knowledge is used to define the criteria to obtain the priorities of the games;

(2) With the help of the developed model, we set the priorities for criteria to prioritize the games;

(3) We prioritize the significance of the three type of medals (gold, silver and bronze), and then use the priorities of games and three type of medals to obtain the total scores of all three types of medals won by each country;

(4) As an illustration of our theory, 2014 Sochi Winter Olympics data are used. It is seen that the ranking of the countries would have been different than the current use of simply adding the number of medals won. The following sections describe the forgoing methodology step by step.

The remainder of this paper is organized as follows: in Sect. 2 we give a brief introduction of how the analytic hierarchy process (AHP) works in the measurement of both tangibles and intangibles; in Sect. 3, we analyze the criteria for determining the priorities of games; in Sect. 4, we construct the model of evaluating the priorities of games, and then make some pairwise comparison (rather than the one-wise way of measurements) judgments to determine the priorities of games and different types of medals; in Sect. 5, we use the obtained priorities to compute the total scores of all three types of medals won by each country to determine the ranking of the countries which won medals in the Sochi Winter Olympics; The paper is concluded in Sect. 6.

\section{How to Evaluate Intangibles-AHP [6]}

A fundamental aspect of the AHP is making paired comparisons of homogeneous activities or items that have a common property with respect to that activity. In making the comparisons, one determines, using expert judgment, how many times more one activity dominated another with respect to a property they share. If the other activity has the property more, the comparisons ask for how many times more the other activity has that property than the first activity. In either case, the smaller or lesser activity is used as a unit and the larger one is estimated as a multiple of that unit. More generally, we speak of the determination of the intensity of importance of one activity over another with respect to the property they have in common. 
Suppose we wish to compare two activities $A$ and $B$. If we believe that activity $A$ is moderately more important than activity $B$, then we say that the intensity of importance of $A$ over $B$ is 3 times and the intensity of importance of $B$ over $A$ is $1 / 3$. In the analysis of the relative importance of gold, silver and bronze Olympic medals if, for example, we believe that a gold medal is moderately more important than a silver medal, then we say that the intensity of importance of a gold medal over a silver medal is 3 times and the intensity of importance of a silver medal to a gold medal is $1 / 3$. When we compare an activity with itself, we assign that comparison the value 1. The intensity of importance or pairwise comparison scale between two activities used in the AHP is given in Table 1.

Unlike the old way of measuring by assigning a number from a fixed scale with an arbitrary unit to each entity or activity, in the new paradigm of measurement of the AHP, the measurements are not fixed but depend on each other and on the context of the problem and its objectives. While things may or may not depend on each other according to their function, they are always interdependent according to measurement in this relative way of pairwise comparisons. The foregoing scale is derived from responses to successive just noticeable stimuli. That theory is itself derivable from neural firing in response to stimuli as a generalization of the pairwise comparisons process to the continuous case [7].

To illustrate that this approach is not arbitrary but relates very closely to the reality of actual measurement, consider a person who would like to estimate the relative area of the five geometric shapes given in Fig. 1. For the purpose of this illustration we also give the relative area inside each shape obtained from actual measurement by using a ruler and dividing each measurement by the sum of all five measurements. Of course, in real life situations, the relative areas would not be known to the person. He must estimate the relative sizes of the figures by comparing them in pairs. A pairwise comparison consists of identifying the figure with the smaller area of the two, and estimating numerically how many times larger the area of the larger figure is than the area of the smaller one using the scale in Table 1. The smaller figure is then assigned the reciprocal value when compared with the larger one. These comparisons are arranged in a five by five matrix as illustrated in Table 2. By convention, we compare the item on the left side of the matrix with that on top. If it is larger, we put the whole number corresponding to the judgment in that cell. If it is smaller, we put the reciprocal value in the cell.

In an $n$-by- $n$ matrix, because of the reciprocals and the ones down the diagonal, $n(n-1) / 2$ judgments must be made. These judgments are made independently, but they are not really "independent". If the square is three times larger than the rectangle and the rectangle is twice times larger than the triangle, then the square should be six times larger than the triangle but here the judgments decided that the square should be five times larger than the triangle. Thus the judgments are inevitably inconsistent. The mathematical expression of our expectation is the set of identities:

$$
a_{i j}=a_{i k} / a_{j k}, \quad \text { for all } i, j,=1,2, \ldots, n
$$

among the entries of a consistent pairwise comparison matrix $A=\left[a_{i j}\right]$. When we have inconsistency, we can identify the most inconsistent judgment and ask the judge if 
Table 1 Fundamental scale of absolute numbers

\begin{tabular}{|c|c|c|}
\hline Intensity of Importance & Definition & Explanation \\
\hline 1 & Equal Importance & $\begin{array}{l}\text { Two activities contribute equally to } \\
\text { the objective }\end{array}$ \\
\hline 2 & Weak or slight & \\
\hline 3 & Moderate importance & $\begin{array}{l}\text { Experience and judgment slightly } \\
\text { favor one activity over another }\end{array}$ \\
\hline 4 & Moderate plus & \\
\hline 5 & Strong importance & $\begin{array}{l}\text { Experience and judgment strongly } \\
\text { favor one activity over another }\end{array}$ \\
\hline 6 & Strong plus & \\
\hline 7 & $\begin{array}{l}\text { Very strong or demonstrated } \\
\text { importance }\end{array}$ & $\begin{array}{l}\text { An activity is favored very strongly } \\
\text { over another; its dominance } \\
\text { demonstrated in practice }\end{array}$ \\
\hline 8 & Very, very strong & \\
\hline 9 & Extreme importance & $\begin{array}{l}\text { The evidence favoring one activity } \\
\text { over another is of the highest } \\
\text { possible order of affirmation }\end{array}$ \\
\hline $1.1-1.9$ & $\begin{array}{l}\text { When activities are very close a } \\
\text { decimal is added to } 1 \text { to show their } \\
\text { difference as appropriate }\end{array}$ & $\begin{array}{l}\text { A better alternative way to assigning } \\
\text { small decimals is to compare two } \\
\text { close activities with other widely } \\
\text { contrasting ones, favoring the } \\
\text { larger one a little over the smaller } \\
\text { one when using the } 1-9 \text { values }\end{array}$ \\
\hline Reciprocals of above & $\begin{array}{l}\text { If activity } i \text { has one of the above } \\
\text { nonzero numbers assigned to it } \\
\text { when compared with activity } j \text {, } \\
\text { then } j \text { has the reciprocal value } \\
\text { when compared with } i\end{array}$ & A logical assumption \\
\hline $\begin{array}{l}\text { Real numbers } \\
\text { between the } \\
\text { above integers }\end{array}$ & & $\begin{array}{l}\text { When appropriate according to the } \\
\text { person making the comparisons } \\
\text { because of special knowledge that } \\
\text { person has }\end{array}$ \\
\hline $\begin{array}{l}\text { Ratios of } \\
\text { measurements } \\
\text { on a ratio scale }\end{array}$ & & $\begin{array}{l}\text { When measurements are available } \\
\text { and one interprets their ratios to be } \\
\text { equivalent to judgments (not } \\
\text { usually recommended). }\end{array}$ \\
\hline
\end{tabular}

he is able to change his mind somewhat to use the recommended value that improves the inconsistency for which we have a measure. We continue the process until the inconsistency is improved adequately as explained in the theory. If he is unable to do that, we cannot continue the exercise because better understanding is needed.

If the judgments are consistent, we derive the priority of each figure in Table 2 by summing the numbers in its row of the matrix and then normalizing it by dividing it by the total sum of all the rows of the matrix and thus obtain the relative sizes of the figures from all the comparison judgments. Table 2 also gives the estimated and actual relative areas resulting from this exercise in the last two columns. They are very close.

When the judgments are acceptably inconsistent, the priorities can be obtained by computing what is known as the principal eigenvector of the matrix. Note the closeness 
Fig. 1 Area example

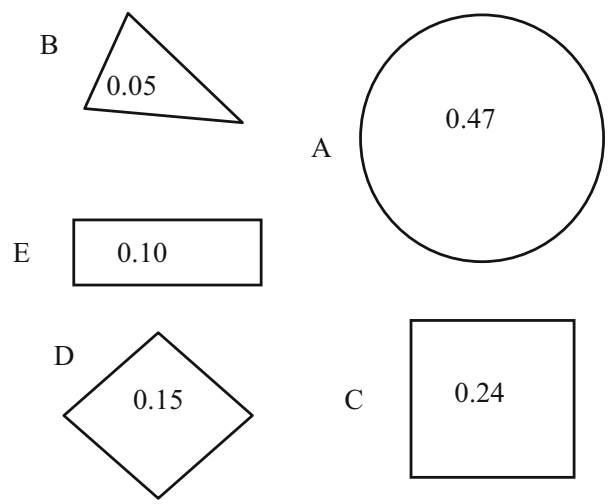

Table 2 Matrix of judgments, outcomes, and actual relative sizes of the five geometric shapes

\begin{tabular}{llllllll}
\hline Figures & Circle & Triangle & Square & Diamond & Rectangle & $\begin{array}{l}\text { Priorities from } \\
\text { comparisons }\end{array}$ & $\begin{array}{l}\text { Actual relative } \\
\text { size }\end{array}$ \\
\hline Circle & 1 & 9 & 2 & 3 & 5 & 0.457 & 0.471 \\
Triangle & $1 / 9$ & 1 & $1 / 5$ & $1 / 3$ & $1 / 2$ & 0.049 & 0.050 \\
Square & $1 / 2$ & 5 & 1 & 2 & 3 & 0.257 & 0.234 \\
Diamond & $1 / 3$ & 3 & $1 / 2$ & 1 & 2 & 0.150 & 0.149 \\
Rectangle & $1 / 5$ & 2 & $1 / 3$ & $1 / 2$ & 1 & 0.087 & 0.096 \\
\hline
\end{tabular}

Inconsistency $=0.003$

of the last two columns in Table 2: the priorities derived from judgments and from the actual measurements. By including more than two alternatives in a decision problem, one is able to obtain better values for the derived scale because of redundancy in the comparisons. Redundancy helps improve the overall accuracy of judgments.

The result of estimating the relative area of the five geometric shapes is that there is a close match between priorities derived from judgments developed by using the eyes and actual measurements. Needless to say, the process needs a certain amount of expertise because a child cannot give such good judgments. We have so many similar examples that they could fill a book. We again illustrate the process with an example that does not rely directly on the senses, like the eye in the area example. Table 3 shows how an audience of about 30 people, using consensus to arrive at each judgment, provided judgments to estimate the dominance of the consumption of drinks in the United States (which drink is consumed more in the US and how much more than another drink?). The derived vector of relative consumption and the actual vector, obtained by normalizing the consumption given in official statistical data sources, are at the last two columns of Table 3. This exercise was done many years ago and again we see that the priorities and the actual measurements available at the time, expressed in relative form, are very close.

Homogeneity, an important concept to ensure consistency in making paired comparisons, requires that the elements be of the same order of magnitude. In this case, 
Table 3 Relative consumption of drinks in the US

\begin{tabular}{llllllllll}
\hline Drinks & Coffee & Wine & Tea & Beer & Soda & Milk & Water & $\begin{array}{l}\text { Priorities from } \\
\text { comparisons }\end{array}$ & $\begin{array}{l}\text { Actual relative } \\
\text { consumption }\end{array}$ \\
\hline Coffee & 1 & 9 & 5 & 2 & 1 & 1 & $1 / 2$ & 0.177 & 0.180 \\
Wine & $1 / 9$ & 1 & $1 / 3$ & $1 / 9$ & $1 / 9$ & $1 / 9$ & $1 / 9$ & 0.019 & 0.010 \\
Tea & $1 / 5$ & 3 & 2 & $1 / 3$ & $1 / 4$ & $1 / 3$ & $1 / 9$ & 0.042 & 0.040 \\
Beer & $1 / 2$ & 9 & 3 & 1 & $1 / 2$ & 1 & $1 / 3$ & 0.116 & 0.120 \\
Soda & 1 & 9 & 4 & 2 & 1 & 2 & $1 / 2$ & 0.190 & 0.180 \\
Milk & 1 & 9 & 3 & 1 & $1 / 2$ & 1 & $1 / 3$ & 0.129 & 0.140 \\
Water & 2 & 9 & 9 & 3 & 2 & 3 & 1 & 0.327 & 0.330 \\
\hline
\end{tabular}

Inconsistency $=0.022$

athletes are trained and challenged in each event to apply their physical strengths and mental abilities skillfully to control their actions, their adroitness and forcefulness to the maximum possible and in diverse ways. Our perceptions in comparing them will be more reliable when they are not too far apart with respect to the criterion in question. It is a fact that people are unable to directly compare widely disparate objects such as a ping-pong ball and a basketball according to volume. There is a way to generalize the approach to comparisons for inhomogeneous elements by putting them in groups or clusters so that two adjacent clusters have a common element needed to make the measurements commensurate, but we don't need to get into it for our purpose here.

\section{Sochi Winter Olympic Events and Criteria to Prioritize Games}

Different Olympic events and categories may take place in different Olympics. In the 2014 Sochi Winter Olympics, 98 official events in 7 games and 15 disciplines were held. They are shown in Table 4, and a total number of 295 medals including 99 gold, 97 silver and 99 bronze medals were awarded. Two gold medals were awarded, one to Slovenia and one to Switzerland, for the first-place tie in the women's downhill competition in alpine skiing event. No silver medal was awarded. Two bronze medals were awarded, one to Canada and one to the United States, for the third-place tie in the men's super-G event in alpine skiing.

The priorities of different kinds of games depend on several factors. First is the environment: social environment, natural environment, living environment and venue environment. Win of medals in a sport needs all the important factors to be met, such as policy support from the home government, investment of money and labor, adaptation to the local environment, audience reaction and so on. The second factor is the people who take part in the sports, including athletes and other related people. For example, team sports need cooperative work and every member may not be good at that. On the other hand, individual sports may need more responsibility and concentration, because, unlike a team sport, each individual takes all responsibilities by himself.

Under each factor, there are sub-factors. The sub-factors of social (the people's) environment are political factors (support from government, including government policy, international situation and political stability), economic factors (does the coun- 


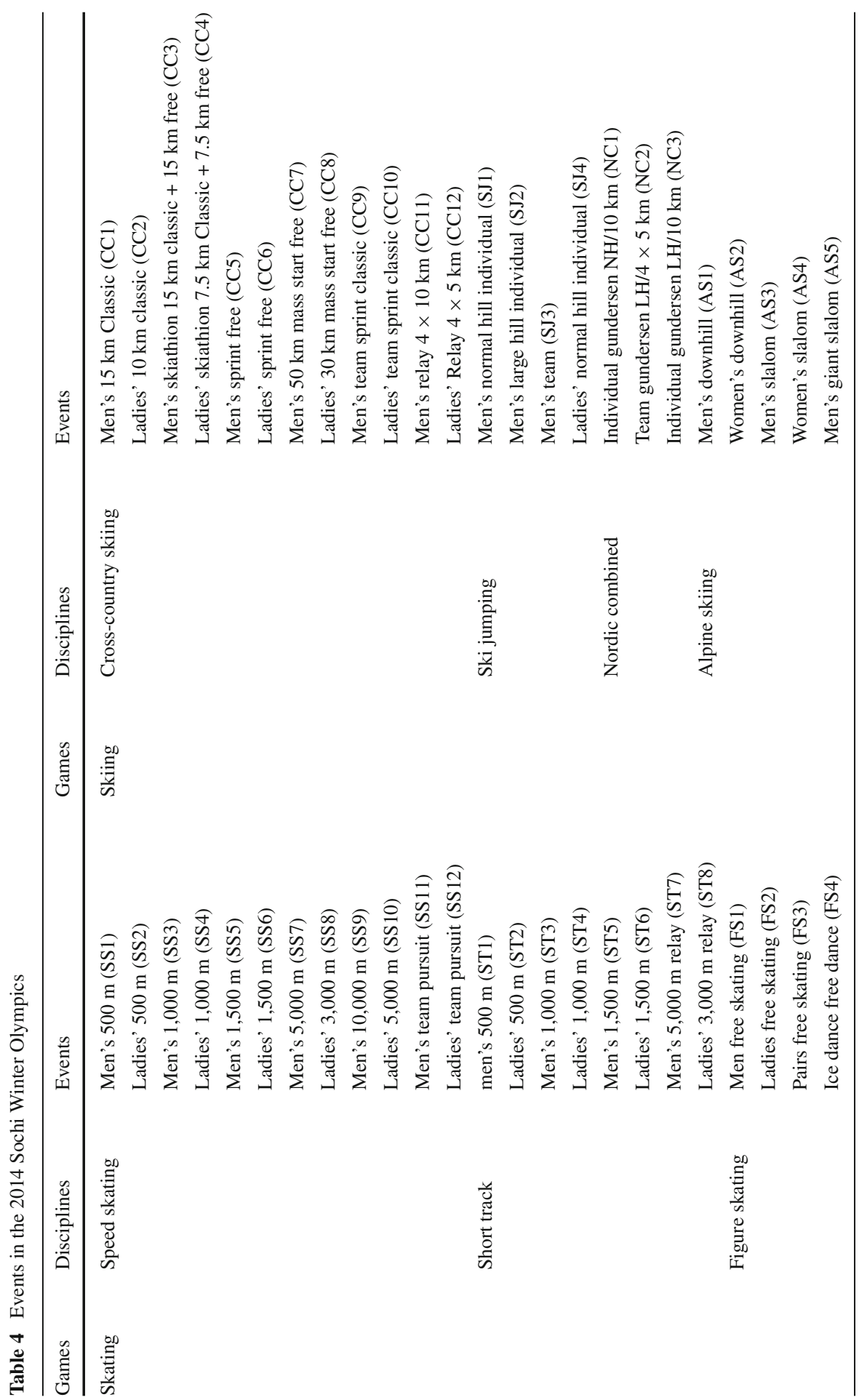




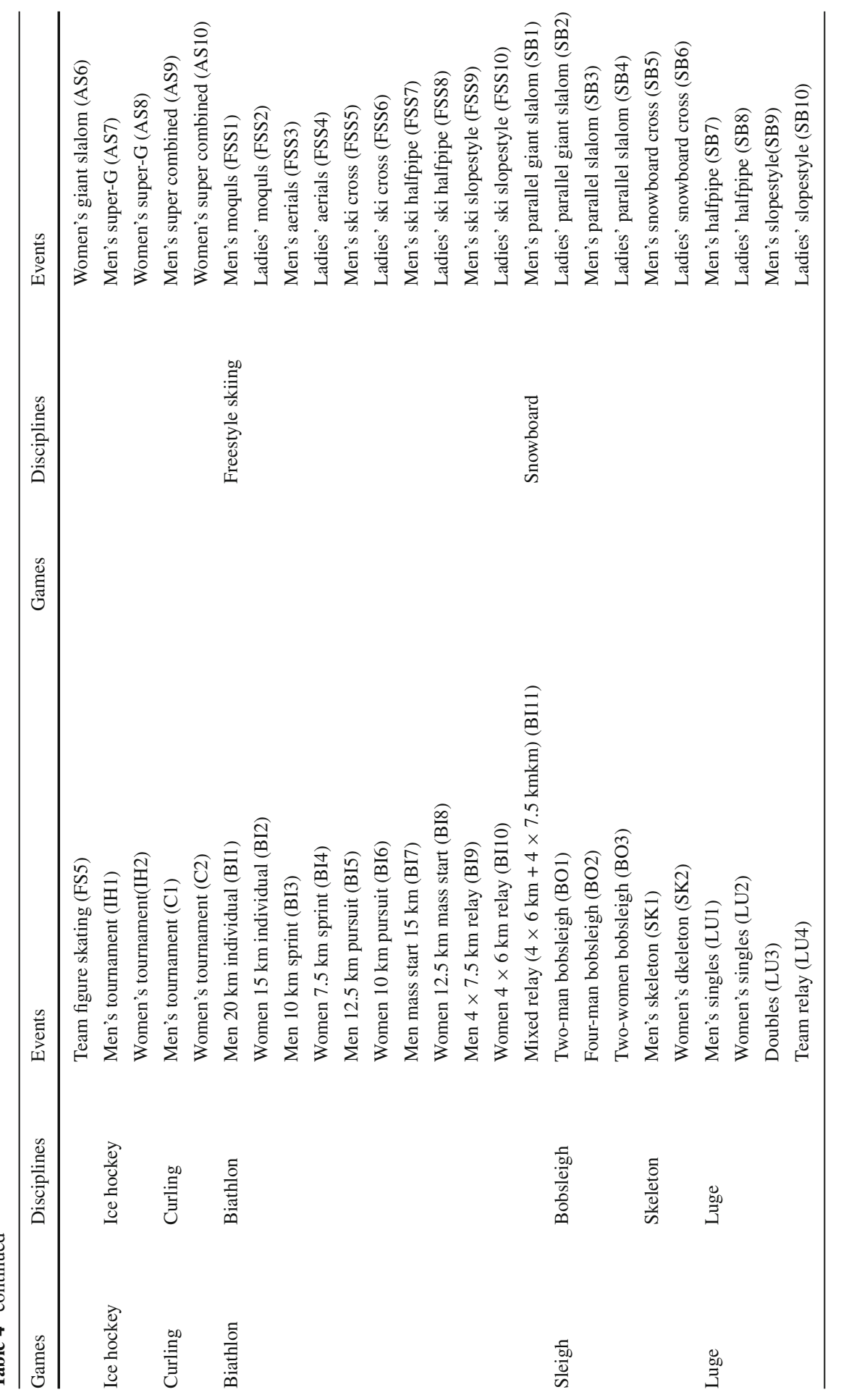


try have sufficient funds to provide the best conditions for the development of sports, including GDP, population, people's income and sports industrialization) and cultural factors (the great sports of each country may be different due to the influences of education, technology, traditional culture, values and race). The sub-factors of natural environment include climate (air pressure, cloud cover, fog, humidity, temperature and wind) and terrain (altitude and topographic pattern). The sub-factors of the living environment consist of diet, entertainment and living. Under venue environment, the sub-factors are equipment familiarity and venue fitness. We also add some sub-factors under the athlete and other related people factor, such as, for the athlete: mood, physical status, psychological quality, responsibility, talent, training time and cooperation, and for other related people: training level of coach, strength of competitors, number of competitors, fairness of referee and audiences' reaction.

Besides we also assign priorities to different types of medals. To do that, we use pairwise comparison judgments as in the AHP examples shown in Sect. 2. Unlike choosing a best alternative in making a decision, the medals in sports are token awards for achievement rather than alternatives with diverse properties.

One thing we do not do here is to take consideration the factors the judges use to evaluate players in events whose outcome is not directly determined by who came in first, second, third etc. For example, in figure skating the judges must decide on the difficulty of performance, its beauty, and coordination whether one or two people are skating and so on. How to do that using the AHP and include it in the actual evaluation of the players requires a separate paper. Here we are concerned with which country is the winner of the overall outcome and not with which player receives what priority in an event.

\section{Applying AHP to Derive the Priorities of Games and Different Types of Medals: An Elaborate Structure of the Model}

No one in the world can be sure about what the relative values of games and medals are, but we can try by estimating their relative importance in several possible and reasonable ways. Here, based on the criteria mentioned above, we use the AHP method to determine the priorities of games and different types of medals including gold, silver and bronze medals, respectively. The method consists of the following steps: interview with the experts about defining the criteria that should be considered to evaluate the priorities of games; obtain the paired comparisons of the criteria and subcriteria by using a previously prepared questionnaire to derive the priority of each kind of game; and make the paired comparisons between different types of medals in different situations and then average the results. Literature research produced several factors to include in our model. Based on the criteria analyzed in Sect. 3, Fig. 2 shows an extensive hierarchic model of the 2014 Sochi Winter Olympics.

In the AHP model, the alternatives are seven kinds of games in the 2014 Sochi Winter Olympics, including skating, ice hockey, curling, biathlon, sleigh, luge and skiing. 


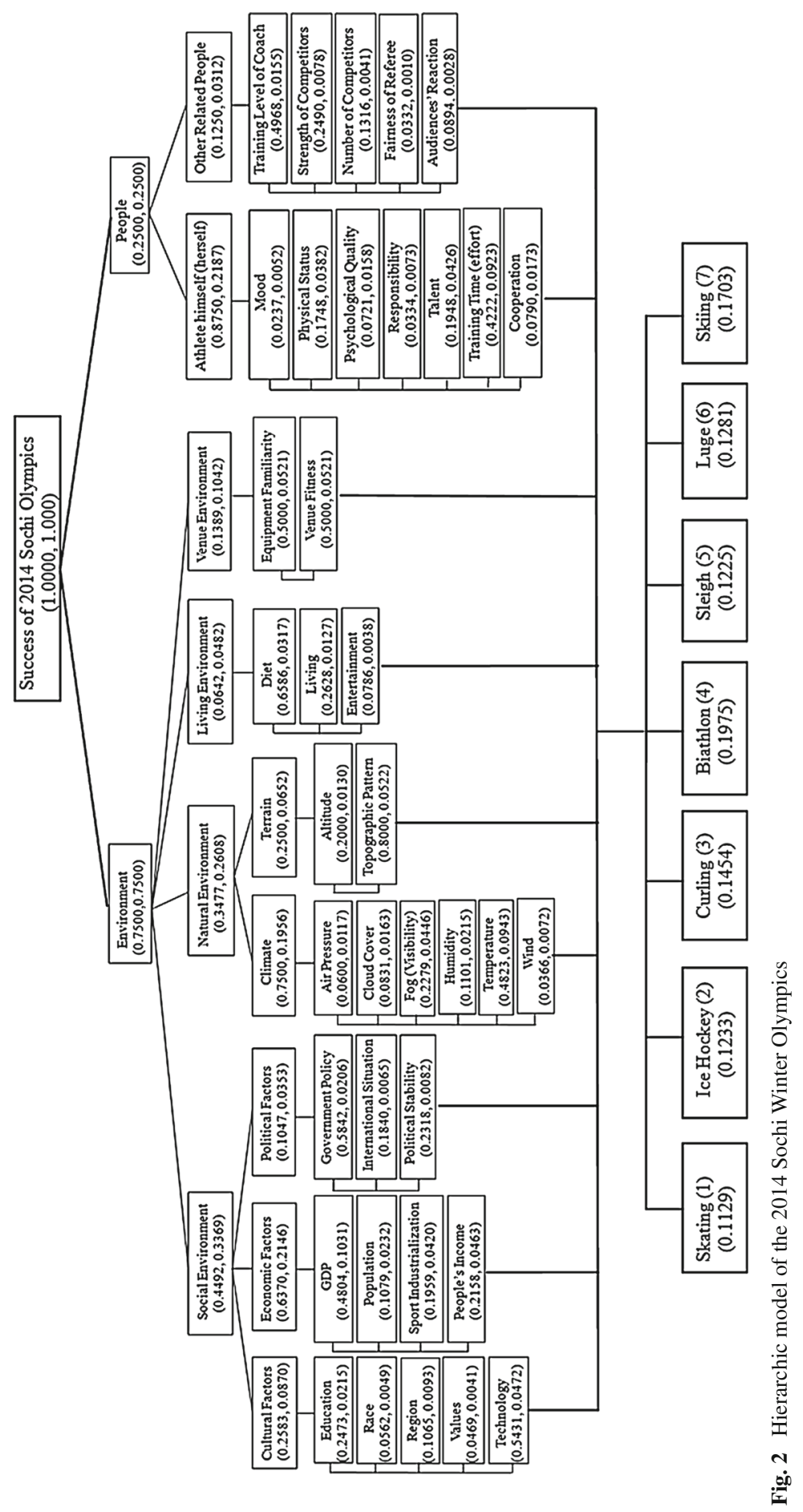


Table 5 Comparisons between criteria under the "success of the 2014 Sochi Winter Olympics

Inconsistency $=0.000$

\begin{tabular}{llll}
\hline Criteria & Environment & People & Priorties \\
\hline Environment & 1 & 3 & 0.7500 \\
People & $1 / 3$ & 1 & 0.2500
\end{tabular}

Table 6 Comparisons between four environmental factors under the criteria "Environment"

\begin{tabular}{llllll}
\hline Environment & $\begin{array}{l}\text { Social } \\
\text { Environment }\end{array}$ & $\begin{array}{l}\text { Natural } \\
\text { Environment }\end{array}$ & $\begin{array}{l}\text { Living } \\
\text { Environment }\end{array}$ & $\begin{array}{l}\text { Venue } \\
\text { Environment }\end{array}$ & Priorities \\
\hline Social Environment & 1 & 2 & 7 & 2 & 0.4492 \\
Natural Environment & $1 / 2$ & 1 & 5 & 4 & 0.3477 \\
Living Environment & $1 / 7$ & $1 / 5$ & 1 & $1 / 2$ & 0.0642 \\
Venue Environment & $1 / 2$ & $1 / 4$ & 2 & 1 & 0.1389 \\
\hline
\end{tabular}

Inconsistency $=0.062$

\subsection{The Priorities of the Games}

To prioritize the games in a reliable way, we used the expert knowledge of the second author to make paired comparison judgments. It took him, an expert in the Winter Olympics, five hours to make all the comparison judgments. He began by comparing in Table 5 the relative importance or dominance of the two criteria "Environment" and "People" with respct to the goal of "Success of the 2014 Sochi Winter Olympics"shown in Fig. 2.

Then, the pairwise comparisons about the importance of the factors in a lower level of the hierarchy are made with respect to the related factor in the level immediately above. For example, with respect to the criterion "Environment" in the second level, the pairwise comparisons between the importance of the environmental factors "Social Environment", "Natural Environment", "Living Environment" and "Venue Environment" are shown in Table 6.

Subsequent to making all the pairwise comparisons hierarchically about the importance of factors in a lower level in Fig. 2 with repsect to each related factor in the level immediatly above, the local priorties of factors in each level of the hierarchy are obtained, followed by the global priority of each factor computed by multiplying the local priority of that factor by the global priority of the parent factor in the level immediatly above.

As shown in Fig. 2, the first value under each factor is the local priority of that factor and the second value is its global priority. For example, the local priority of the factor "Social Environment" in the third level is 0.4492 and the global priority of its parent factor "Environment" in the second level is 0.7500 , and thus the global priority of "Social Environment" is $0.4492 \times 0.7500=0.3369$.

Finally, the local priorities of the games in the bottom level of the hierarchy in Fig. 2 when compared with respect to the factors in the level immediately above as to the impact of that factor in playing that game, are shown in Table 8. To save space, 
Table 7 Comparisons between seven games with respect to "Technology"

\begin{tabular}{lllllllll}
\hline Games & Skating & Ice hockey & Curling & Biathlon & Sleigh & Luge & Skiing & Priorities \\
\hline Skating & 1 & 2 & 7 & 4 & 2 & 2 & 2 & 0.2682 \\
Ice hockey & $1 / 2$ & 1 & 6 & 3 & $1 / 3$ & $1 / 2$ & $1 / 3$ & 0.1044 \\
Curling & $1 / 7$ & $1 / 6$ & 1 & $1 / 5$ & $1 / 7$ & $1 / 6$ & $1 / 7$ & 0.0235 \\
Biathlon & $1 / 4$ & $1 / 3$ & 5 & 1 & $1 / 4$ & $1 / 3$ & $1 / 3$ & 0.0606 \\
Sleigh & $1 / 2$ & 3 & 7 & 4 & 1 & 1 & 1 & 0.1902 \\
Luge & $1 / 2$ & 2 & 6 & 3 & 1 & 1 & $1 / 2$ & 0.1508 \\
Skiing & $1 / 2$ & 3 & 7 & 3 & 1 & 2 & 1 & 0.2023 \\
\hline
\end{tabular}

Inconsistency $=0.043$

we do not include all the pairwise comparison matrices but illustrate with only one in Table 7 with respect to "Technology.

The global priorities of the games under each factor in the level immediatly above can be obtained by multiplying the local priorities of the games under each factor by the global priority of that factor, as shown in Table 9. For example, the local priority of the game "Skating" under the factor "Education" is 0.0554 and the global priority of the factor "Education" is 0.0215 , so the global priority of the game "Skating" under the factor "Education" is $0.0554 \times 0.0215=0.0012$.

The global priority of each game with respect to the goal "Success of the 2014 Sochi Winter Olympics" can be obtained by summing the global priorities of each game under all the factors in the level immediately above as shown in Table 10.

\subsection{The Priorities of Different Types of Medals [5]}

Here are fourteen sets of comparisons and their actual outcomes shown in Tables 11, $12,13,14,15,16$ and 17 . The reader hopefully excluding the first set of comparisons we already talked about in the introduction, should look at the remaining thirteen to determine which ones are more reasonable. From the pairwise comparison judgments between different types of medals, we can get the priorities of different types of medals under 13 possible situations and then average them to derive the priorities of gold, silver and bronze medals.

In Table 11, the gold, silver and bronze medals have equal value.

In Table 12, the gold medal is very slightly favored over the silver medal and regardless of whether it is moderately or extremely favored over the bronze medals.

Table 13 shows that the gold medal is moderately favored over the silver medal and from very strongly to extremely over the bronze medal, no matter whether the silver medal is moderately or strongly favored over the bronze medal.

In Table 14, the strength of the gold medal over the silver medal increases even more to between moderately and strongly and the gold medal is favored from a little over strongly to extremely over the bronze medal, while the silver medal is only moderately favored over the bronze medal in both cases. 
Table 8 Local priorities of the games under each factor in the level immediately above

\begin{tabular}{|c|c|c|c|c|c|c|c|}
\hline Factors & Skating & Ice hockey & Curling & Biathlon & Sleigh & Luge & Skiing \\
\hline Education (0.0215) & 0.0554 & 0.0366 & 0.4240 & 0.2017 & 0.0725 & 0.0989 & 0.1109 \\
\hline Race (0.0049) & 0.1429 & 0.1429 & 0.1429 & 0.1429 & 0.1429 & 0.1429 & 0.1429 \\
\hline Region (0.0093) & 0.1429 & 0.1429 & 0.1429 & 0.1429 & 0.1429 & 0.1429 & 0.1429 \\
\hline Values $(0.0041)$ & 0.1429 & 0.1429 & 0.1429 & 0.1429 & 0.1429 & 0.1429 & 0.1429 \\
\hline Technology (0.0472) & 0.2682 & 0.1044 & 0.0235 & 0.0606 & 0.1902 & 0.1508 & 0.2023 \\
\hline $\operatorname{GDP}(0.1031)$ & 0.0989 & 0.2474 & 0.3941 & 0.1068 & 0.0550 & 0.0469 & 0.0509 \\
\hline Population (0.0232) & 0.1429 & 0.1429 & 0.1429 & 0.1429 & 0.1429 & 0.1429 & 0.1429 \\
\hline Sports industrialization $(0.0420)$ & 0.1429 & 0.1429 & 0.1429 & 0.1429 & 0.1429 & 0.1429 & 0.1429 \\
\hline People's income (0.0463) & 0.0498 & 0.1501 & 0.2723 & 0.2227 & 0.0706 & 0.0706 & 0.1639 \\
\hline Government policy (0.0206) & 0.1429 & 0.1429 & 0.1429 & 0.1429 & 0.1429 & 0.1429 & 0.1429 \\
\hline International situation $(0.0065)$ & 0.1429 & 0.1429 & 0.1429 & 0.1429 & 0.1429 & 0.1429 & 0.1429 \\
\hline Political stability (0.0082) & 0.1429 & 0.1429 & 0.1429 & 0.1429 & 0.1429 & 0.1429 & 0.1429 \\
\hline Air pressure $(0.0117)$ & 0.1429 & 0.1429 & 0.1429 & 0.1429 & 0.1429 & 0.1429 & 0.1429 \\
\hline Cloud cover $(0.0163)$ & 0.1429 & 0.1429 & 0.1429 & 0.1429 & 0.1429 & 0.1429 & 0.1429 \\
\hline Fog (visibility) (0.0446) & 0.0337 & 0.0286 & 0.0367 & 0.4059 & 0.1013 & 0.1013 & 0.2925 \\
\hline Humidity (0.0215) & 0.1429 & 0.1429 & 0.1429 & 0.1429 & 0.1429 & 0.1429 & 0.1429 \\
\hline Temperature (0.0943) & 0.0367 & 0.0379 & 0.0379 & 0.4186 & 0.1121 & 0.1148 & 0.2420 \\
\hline Wind (0.0072) & 0.0336 & 0.0336 & 0.0336 & 0.2570 & .2140 & 0.2140 & 0.2140 \\
\hline Altitude (0.0130) & 0.0383 & 0.0425 & 0.0425 & 0.3060 & 0.1511 & 0.1572 & 0.2624 \\
\hline Topographic pattern $(0.0522)$ & 0.0278 & 0.0278 & 0.0302 & 0.2329 & 0.1007 & 0.0966 & 0.4840 \\
\hline Diet (0.0317) & 0.1429 & 0.1429 & 0.1429 & 0.1429 & 0.1429 & 0.1429 & 0.1429 \\
\hline Living (0.0127) & 0.0921 & 0.3711 & 0.0297 & 0.1947 & 0.0546 & 0.0546 & 0.2032 \\
\hline Entertainment (0.0038) & 0.1429 & 0.1429 & 0.1429 & 0.1429 & 0.1429 & 0.1429 & 0.1429 \\
\hline Equipment familiarity (0.0521) & 0.0590 & 0.0339 & 0.0470 & 0.1443 & 0.2940 & 0.2939 & 0.1279 \\
\hline Venue fitness $(0.0521)$ & 0.0780 & 0.0488 & 0.0488 & 0.2061 & 0.2061 & 0.2061 & 0.2061 \\
\hline Mood (0.0052) & 0.1429 & 0.1429 & 0.1429 & 0.1429 & 0.1429 & 0.1429 & 0.1429 \\
\hline Physical status (0.0382) & 0.1429 & 0.1429 & 0.1429 & 0.1429 & 0.1429 & 0.1429 & 0.1429 \\
\hline Psychological quality (0.0158) & 0.1429 & 0.1429 & 0.1429 & 0.1429 & 0.1429 & 0.1429 & 0.1429 \\
\hline Responsibility (0.0073) & 0.1429 & 0.1429 & 0.1429 & 0.1429 & 0.1429 & 0.1429 & 0.1429 \\
\hline Talent $(0.0426)$ & 0.2132 & 0.0410 & 0.0410 & 0.3436 & 0.0854 & 0.1281 & 0.1477 \\
\hline Training time (Effort) (0.0923) & 0.1800 & 0.1956 & 0.1956 & 0.1595 & 0.0552 & 0.1158 & 0.0983 \\
\hline Cooperation $(0.0173)$ & 0.1310 & 0.3270 & 0.3270 & 0.0314 & 0.0487 & 0.0626 & 0.0723 \\
\hline Training level of coach (0.0155) & 0.1429 & 0.1429 & 0.1429 & 0.1429 & 0.1429 & 0.1429 & 0.1429 \\
\hline Strength of competitors $(0.0078)$ & 0.1429 & 0.1429 & 0.1429 & 0.1429 & 0.1429 & 0.1429 & 0.1429 \\
\hline Number of competitors $(0.0041)$ & 0.1429 & 0.1429 & 0.1429 & 0.1429 & 0.1429 & 0.1429 & 0.1429 \\
\hline Fairness of referee $(0.0010)$ & 0.1429 & 0.1429 & 0.1429 & 0.1429 & 0.1429 & 0.1429 & 0.1429 \\
\hline Audiences' reaction $(0.0028)$ & 0.1661 & 0.3088 & 0.3088 & 0.0536 & 0.0536 & 0.0555 & 0.0536 \\
\hline
\end{tabular}


Table 9 Global priorities of the games under each factor in the level immediately above

\begin{tabular}{|c|c|c|c|c|c|c|c|}
\hline Factors & Skating & Ice hockey & Curling & Biathlon & Sleigh & Luge & Skiing \\
\hline Education (0.0215) & 0.0012 & 0.0008 & 0.0091 & 0.0043 & 0.0016 & 0.0021 & 0.0024 \\
\hline Race (0.0049) & 0.0007 & 0.0007 & 0.0007 & 0.0007 & 0.0007 & 0.0007 & 0.0007 \\
\hline Region (0.0093) & 0.0013 & 0.0013 & 0.0013 & 0.0013 & 0.0013 & 0.0013 & 0.0013 \\
\hline Values $(0.0041)$ & 0.0006 & 0.0006 & 0.0006 & 0.0006 & 0.0006 & 0.0006 & 0.0006 \\
\hline Technology $(0.0472)$ & 0.0127 & 0.0049 & 0.0011 & 0.0029 & 0.0090 & 0.0071 & 0.0095 \\
\hline GDP $(0.1031)$ & 0.0102 & 0.0255 & 0.0406 & 0.0110 & 0.0057 & 0.0048 & 0.0052 \\
\hline Population (0.0232) & 0.0033 & 0.0033 & 0.0033 & 0.0033 & 0.0033 & 0.0033 & 0.0033 \\
\hline Sports industrialization $(0.0420)$ & 0.0060 & 0.0060 & 0.0060 & 0.0060 & 0.0060 & 0.0060 & 0.0060 \\
\hline People's income (0.0463) & 0.0023 & 0.0069 & 0.0126 & 0.0103 & 0.0033 & 0.0033 & 0.0076 \\
\hline Government policy (0.0206) & 0.0029 & 0.0029 & 0.0029 & 0.0029 & 0.0029 & 0.0029 & 0.0029 \\
\hline International situation (0.0065) & 0.0009 & 0.0009 & 0.0009 & 0.0009 & 0.0009 & 0.0009 & 0.0009 \\
\hline Political stability (0.0082) & 0.0012 & 0.0012 & 0.0012 & 0.0012 & 0.0012 & 0.0012 & 0.0012 \\
\hline Air pressure $(0.0117)$ & 0.0017 & 0.0017 & 0.0017 & 0.0017 & 0.0017 & 0.0017 & 0.0017 \\
\hline Cloud cover $(0.0163)$ & 0.0023 & 0.0023 & 0.0023 & 0.0023 & 0.0023 & 0.0023 & 0.0023 \\
\hline Fog (visibility) (0.0446) & 0.0015 & 0.0013 & 0.0016 & 0.0181 & 0.0045 & 0.0045 & 0.0130 \\
\hline Humidity (0.0215) & 0.0031 & 0.0031 & 0.0031 & 0.0031 & 0.0031 & 0.0031 & 0.0031 \\
\hline Temperature (0.0943) & 0.0035 & 0.0036 & 0.0036 & 0.0395 & 0.0106 & 0.0108 & 0.0228 \\
\hline Wind $(0.0072)$ & 0.0002 & 0.0002 & 0.0002 & 0.0019 & 0.0015 & 0.0015 & 0.0015 \\
\hline Altitude (0.0130) & 0.0005 & 0.0006 & 0.0006 & 0.0040 & 0.0020 & 0.0020 & 0.0034 \\
\hline Topographic pattern $(0.0522)$ & 0.0015 & 0.0015 & 0.0016 & 0.0122 & 0.0053 & 0.0050 & 0.0253 \\
\hline Diet $(0.0317)$ & 0.0045 & 0.0045 & 0.0045 & 0.0045 & 0.0045 & 0.0045 & 0.0045 \\
\hline Living (0.0127) & 0.0012 & 0.0047 & 0.0004 & 0.0025 & 0.0007 & 0.0007 & 0.0026 \\
\hline Entertainment $(0.0038)$ & 0.0005 & 0.0005 & 0.0005 & 0.0005 & 0.0005 & 0.0005 & 0.0005 \\
\hline Equipment familiarity (0.0521) & 0.0031 & 0.0018 & 0.0024 & 0.0075 & 0.0153 & 0.0153 & 0.0067 \\
\hline Venue fitness $(0.0521)$ & 0.0041 & 0.0025 & 0.0025 & 0.0107 & 0.0107 & 0.0107 & 0.0107 \\
\hline Mood (0.0052) & 0.0007 & 0.0007 & 0.0007 & 0.0007 & 0.0007 & 0.0007 & 0.0007 \\
\hline Physical status (0.0382) & 0.0055 & 0.0055 & 0.0055 & 0.0055 & 0.0055 & 0.0055 & 0.0055 \\
\hline Psychological quality (0.0158) & 0.0023 & 0.0023 & 0.0023 & 0.0023 & 0.0023 & 0.0023 & 0.0023 \\
\hline Responsibility (0.0073) & 0.0010 & 0.0010 & 0.0010 & 0.0010 & 0.0010 & 0.0010 & 0.0010 \\
\hline Talent $(0.0426)$ & 0.0091 & 0.0017 & 0.0017 & 0.0146 & 0.0036 & 0.0055 & 0.0063 \\
\hline Training time (Effort) (0.0923) & 0.0166 & 0.0181 & 0.0181 & 0.0147 & 0.0051 & 0.0107 & 0.0091 \\
\hline Cooperation $(0.0173)$ & 0.0023 & 0.0057 & 0.0057 & 0.0005 & 0.0008 & 0.0011 & 0.0013 \\
\hline Training level of coach $(0.0155)$ & 0.0022 & 0.0022 & 0.0022 & 0.0022 & 0.0022 & 0.0022 & 0.0022 \\
\hline Strength of competitors $(0.0078)$ & 0.0011 & 0.0011 & 0.0011 & 0.0011 & 0.0011 & 0.0011 & 0.0011 \\
\hline Number of competitors $(0.0041)$ & 0.0006 & 0.0006 & 0.0006 & 0.0006 & 0.0006 & 0.0006 & 0.0006 \\
\hline Fairness of referee $(0.0010)$ & 0.0001 & 0.0001 & 0.0001 & 0.0001 & 0.0001 & 0.0001 & 0.0001 \\
\hline Audiences' reaction $(0.0028)$ & 0.0005 & 0.0009 & 0.0009 & 0.0002 & 0.0002 & 0.0002 & 0.0002 \\
\hline Total global priorities & 0.1129 & 0.1233 & 0.1454 & 0.1975 & 0.1225 & 0.1281 & 0.1703 \\
\hline
\end{tabular}


Table 10 The global priority of each game in the 2014 Sochi Winter Olympics

\begin{tabular}{llll}
\hline Games & Priorities & Games & Priorities \\
\hline Skating & 0.1129 & Sleigh & 0.1225 \\
Ice hockey & 0.1233 & Luge & 0.1281 \\
Curling & 0.1454 & Skiing & 0.1703 \\
Biathlon & 0.1975 & & \\
\hline
\end{tabular}

Table 11 Tables with gold, silver and bronze medals equally important

\begin{tabular}{lllll}
\hline & Gold & Silver & Bronze & Relative values \\
\hline Gold & 1 & 1 & 1 & 0.33 \\
Silver & 1 & 1 & 1 & 0.33 \\
Bronze & 1 & 1 & 1 & 0.33 \\
\hline
\end{tabular}

Table 12 Gold slightly over silver

Table 13 Gold moderately over silver

\begin{tabular}{lllll}
\hline & Gold & Silver & Bronze & Relative values \\
\hline Gold & 1 & 3 & 7 & 0.64 \\
Silver & $1 / 3$ & 1 & 3 & 0.26 \\
Bronze & $1 / 7$ & $1 / 3$ & 1 & 0.10 \\
\hline Gold & 1 & 3 & 7 & 0.65 \\
Silver & $1 / 3$ & 1 & 5 & 0.28 \\
Bronze & $1 / 7$ & $1 / 5$ & 1 & 0.07 \\
\hline Gold & 1 & 3 & 9 & 0.67 \\
Silver & $1 / 3$ & 1 & 3 & 0.27 \\
Bronze & $1 / 9$ & $1 / 3$ & 1 & 0.06 \\
\hline
\end{tabular}

In Table 15, the gold medal is strongly favored over the silver medal and very strongly to extremely important over the bronze medal.

In Table 16, the gold medal is considered strongly more important than the silver medal and extremely more than the bronze medal while the silver medal is first moderately and then between moderately and strongly more important over the bronze medal. 
Table 14 Gold between moderately and strongly over silver

Table 15 Gold strongly over silver

Table 16 Gold very strongly over silver

Table 17 Gold extremely over silver

\begin{tabular}{lllll}
\hline & Gold & Silver & Bronze & Relative values \\
\hline Gold & 1 & 4 & 6 & 0.69 \\
Silver & $1 / 4$ & 1 & 3 & 0.22 \\
Bronze & $1 / 6$ & $1 / 3$ & 1 & 0.09 \\
\hline Gold & 1 & 4 & 9 & 0.73 \\
Silver & $1 / 4$ & 1 & 3 & 0.20 \\
Bronze & $1 / 9$ & $1 / 3$ & 1 & 0.07 \\
\hline
\end{tabular}

\begin{tabular}{lllll}
\hline & Gold & Silver & Bronze & Relative values \\
\hline Gold & 1 & 5 & 7 & 0.72 \\
Silver & $1 / 5$ & 1 & 4 & 0.21 \\
Bronze & $1 / 7$ & $1 / 4$ & 1 & 0.07 \\
\hline Gold & 1 & 5 & 9 & 0.74 \\
Silver & $1 / 5$ & 1 & 4 & 0.19 \\
Bronze & $1 / 9$ & $1 / 4$ & 1 & 0.07 \\
\hline
\end{tabular}

\begin{tabular}{lllll}
\hline & Gold & Silver & Bronze & Relative values \\
\hline Gold & 1 & 7 & 9 & 0.79 \\
Silver & $1 / 7$ & 1 & 3 & 0.15 \\
Bronze & $1 / 9$ & $1 / 3$ & 1 & 0.06 \\
\hline Gold & 1 & 7 & 9 & 0.78 \\
Silver & $1 / 7$ & 1 & 4 & 0.16 \\
Bronze & $1 / 9$ & $1 / 4$ & 1 & 0.06 \\
\hline
\end{tabular}

\begin{tabular}{lllll}
\hline & Gold & Silver & Bronze & Relative values \\
\hline Gold & 1 & 9 & 9 & 0.80 \\
Silver & $1 / 9$ & 1 & 5 & 0.15 \\
Bronze & $1 / 9$ & $1 / 5$ & 1 & 0.05 \\
\hline Gold & 1 & 9 & 9 & 0.78 \\
Silver & $1 / 9$ & 1 & 9 & 0.18 \\
Bronze & $1 / 9$ & $1 / 9$ & 1 & 0.04 \\
\hline
\end{tabular}

In Table 17, the gold medal is extremely important over the silver medal and the bronze medal while the silver medal is first strongly important and then extremely important over the bronze medal. 
Table 18 The 13 vectors of priorities from Tables 12, 13, 14, 15, 16 and 17 and their average

\begin{tabular}{lllllllllllllllllll}
\hline \multicolumn{1}{c}{ 13 Different situations } \\
\hline Gold & 0.55 & 0.61 & 0.64 & 0.65 & 0.67 & 0.69 & 0.73 & 0.72 & 0.74 & 0.79 & 0.78 & 0.80 & 0.78 & 9.15 & 0.7040 \\
Silver & 0.27 & 0.32 & 0.26 & 0.28 & 0.27 & 0.22 & 0.20 & 0.21 & 0.19 & 0.15 & 0.16 & 0.15 & 0.18 & 2.86 & 0.2200 \\
Bronze & 0.18 & 0.07 & 0.10 & 0.07 & 0.06 & 0.09 & 0.07 & 0.07 & 0.07 & 0.06 & 0.06 & 0.05 & 0.04 & 0.99 & 0.0760 \\
\hline
\end{tabular}

Table 19 The weighted priorities of medals won in each game

\begin{tabular}{|c|c|c|c|}
\hline \multirow[t]{2}{*}{ Games } & \multicolumn{3}{|c|}{$\begin{array}{l}\text { Weighted priorities of medals using } \\
\text { the priority of the game on the left }\end{array}$} \\
\hline & Gold (0.704) & Silver (0.220) & Bronze (0.076) \\
\hline Skating (0.1129) & 0.0795 & 0.0248 & 0.0086 \\
\hline Ice hockey $(0.1233)$ & 0.0868 & 0.0271 & 0.0094 \\
\hline Curling (0.1454) & 0.1024 & 0.0320 & 0.0111 \\
\hline Biathlon (0.1975) & 0.1390 & 0.0435 & 0.0150 \\
\hline Sleigh (0.1225) & 0.0862 & 0.0270 & 0.0093 \\
\hline Luge $(0.1281)$ & 0.0902 & 0.0282 & 0.0097 \\
\hline Skiing (0.1703) & 0.1199 & 0.0375 & 0.0129 \\
\hline
\end{tabular}

The Tables given above give the priorities of different types of medals under 13 different situations shown in Tables 12,13,14, 15, 16 and 17, and then the priorities of different types of medals are obtained by averaging of the priorities derived from the judgment matrices above as shown in the last column of Table 18.

\section{Synthesis of Priorities}

In this paper, we suppose that the disciplines under the same game and the events under the same discipline are euqually important, that is to say, the priorities of events in one game are same as the priority of the game to which they belong. Now, we develp the weighted priorities of different types of medals won in each game by mutiplying the derived priorities of the medals by the priority of the corresponding game as shown in Table 19.

Finally, we are ready to re-rank the countries that won medals in the 2014 Sochi Winter Olympics according to the sum of the weighed priorities of the medals won by each country. This method considers not only the priorities of the games but also the priorities of different types of medals. Taking the Russian. Federation as an example, Table 20 shows how to calculate the total score of the Russian. Fed.

Currently, countries are ranked as in the next-to-last column of Table 21 by just counting the total number of medals they won. Russia is the top ranking country followed by the United States and Norway is third.

Based on our finer approach, the ranking of the countires which won medals in the 2014 Sochi Winter Olympics is shown in the last column of Table 21 and differs 


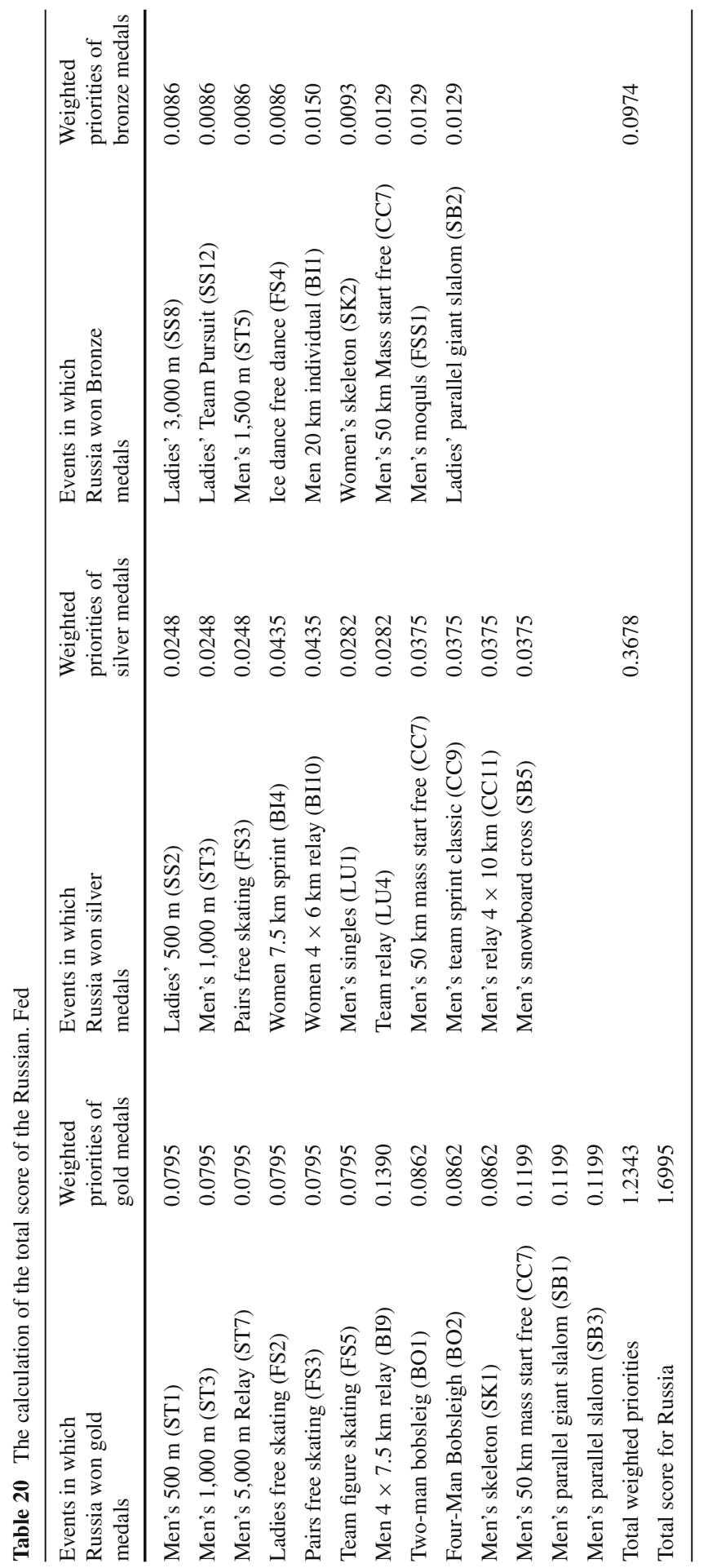


Table 21 Ranking of countries won medals in 2014 Sochi Winter Olympics

\begin{tabular}{|c|c|c|c|c|c|c|c|}
\hline Countries & Gold & Silver & Bronze & $\begin{array}{l}\text { Total } \\
\text { medals }\end{array}$ & $\begin{array}{l}\text { Total weighted } \\
\text { priorities } \\
\text { (scores) }\end{array}$ & $\begin{array}{l}\text { Ranking } \\
\text { according } \\
\text { to total medals }\end{array}$ & $\begin{array}{l}\text { Ranking } \\
\text { according } \\
\text { to total scores }\end{array}$ \\
\hline Russian Fed. & 13 & 11 & 9 & 33 & 1.6995 & 1 & 2 \\
\hline United States & 9 & 7 & 12 & 28 & 1.3900 & 2 & 4 \\
\hline Norway & 11 & 5 & 10 & 26 & 1.7029 & 3 & 1 \\
\hline Canada & 10 & 10 & 5 & 25 & 1.3911 & 4 & 3 \\
\hline Netherlands & 8 & 7 & 9 & 24 & 0.8870 & 5 & 6 \\
\hline Germany & 8 & 6 & 5 & 19 & 1.1284 & 6 & 5 \\
\hline Austria & 4 & 8 & 5 & 17 & 0.8429 & 7 & 8 \\
\hline France & 4 & 4 & 7 & 15 & 0.7662 & 8 & 9 \\
\hline Sweden & 2 & 7 & 6 & 15 & 0.5620 & 9 & 11 \\
\hline Switzerland & 6 & 3 & 2 & 11 & 0.8497 & 10 & 7 \\
\hline China & 3 & 4 & 2 & 9 & 0.3719 & 11 & 14 \\
\hline Korea & 3 & 3 & 2 & 8 & 0.3301 & 12 & 16 \\
\hline Czech Republic & 2 & 4 & 2 & 8 & 0.3847 & 13 & 13 \\
\hline Slovenia & 2 & 2 & 4 & 8 & 0.3685 & 14 & 15 \\
\hline Japan & 1 & 4 & 3 & 8 & 0.2682 & 15 & 17 \\
\hline Italy & 0 & 2 & 6 & 8 & 0.1257 & 16 & 22 \\
\hline Belarus & 5 & 0 & 1 & 6 & 0.6718 & 17 & 10 \\
\hline Poland & 4 & 1 & 1 & 6 & 0.4726 & 18 & 12 \\
\hline Finland & 1 & 3 & 1 & 5 & 0.2411 & 19 & 18 \\
\hline Great Britain & 1 & 1 & 2 & 4 & 0.1422 & 20 & 20 \\
\hline Latvia & 0 & 2 & 2 & 4 & 0.0734 & 21 & 24 \\
\hline Australia & 0 & 2 & 1 & 3 & 0.0879 & 22 & 23 \\
\hline Ukraine & 1 & 0 & 1 & 2 & 0.1540 & 23 & 19 \\
\hline Slovakia & 1 & 0 & 0 & 1 & 0.1390 & 24 & 21 \\
\hline Croatia & 0 & 1 & 0 & 1 & 0.0375 & 25 & 25 \\
\hline Kazakhstan & 0 & 0 & 1 & 1 & 0.0086 & 26 & 26 \\
\hline Grand totals & 99 & 97 & 99 & 295 & 15.0969 & & \\
\hline
\end{tabular}

somewhat from the ranking obtained by the traditional method. Here, Norway is first and the second and third conutries are the Russian Fed. and Canada, respectively. For many countries rank order changes. For example, Belarus was ranked 17th on total medals, but now ranks 10th; On the other hand, Italy, originally ranked 16th, is now ranked 22nd. It is noted that Belarus only won 6 medals whereas Italy won 8, yet Belarus ranks higher than Italy. The reason for this conclusion is that Belarus received 5 gold medals which have higher priorities in all games, while Italy did not receive a gold medal and only won 2 silver medals and 6 bronze medals which have relatively lower priorities. So the country that has more total medals like Italy may not get a higher total score than one with fewer medals with greater priorities like Belarus. 
It truns out that Norway won because most of the medals it won are from the games of Biathlon and Skiing which have higher priorities than Skating and Sleigh for which Russia won the most medals according to the priorities of games derived in our AHP model.

\section{Conclusions}

Training for competition in the Olympics needs time and resources. Different types of events may have different characteristics. Individual games need more concentration, team ones need more cooperation. This way of thinking emphasizes the idea that each game has different characteristics and the result is always influenced by many factors from the environment and the people involved, so these factors should be considered when we quantify the values of different kinds of games.

Our paper has proposed a more systematic way to determine the ranking of the countries that won medals in the 2014 Sochi Winter Olympics than the one currently used. The conclusion is that the ranking of countries should not only be determined by counting the total medals won, but also the types of medals which are won. Motivated by this idea, we utilize the AHP method by the priorities of the games according to the factors that take the environment and the people into consideration. This approach could change the previous rankings in Olympics history as we also observed here for the 2014 Sochi Winter Olympics.

Ranking, particularly of intangibles, is always subjective-subject to different considerations, the time, the environment, and other pet ideas that are ever changing. The AHP is an effective and timely approach to make such rankings because it can be easily adapted to make the necessary changes.

\section{References}

1. Bernard AB, Busse MR (2000) Who wins the Olympic games: economic development and medal total. NBER Working Paper No. 7998. Issued in November

2. Bialek C (2008) Who won the Olympics medal count? Let me count the ways. http://blogs.wsj.com/ numbersguy $/ \mathrm{s}=$ olympics $\& \mathrm{x}=13 \& \mathrm{y}=10 \&$ paged $=2$. Accessed 25 Aug 2008

3. Forsyth S (2008) China 2008 Olympic medal tally by population, and China 2008 Olympic medal tally by gross domestic product (GDP). http://simon.forsyth.net/olympics.html

4. The World Factbook (ISSN 1553-8133; an annual publication also known as the CIA World Factbook) a two- to three-page summary of the demographics, geography, communications, government, economy, and military of 266 U.S.-recognized countries, dependencies, and other areas in the world

5. Saaty TL (2008) Who won the 2008 Olympics? J Syst Sci Syst Eng 17(4):473-486

6. Saaty TL (1982) Decision making for leaders; The analytic hierarchy process for decisions in a complex world. Wadsworth (Translated to French, Indonesian, Spanish, Korean, Arabic, Persian, Thai. Latest revised version, RWS Publications, Pittsburgh, 2000)

7. Saaty TL (2010) Principia mathematica decernendi. RWS Publications, Pittsburgh 


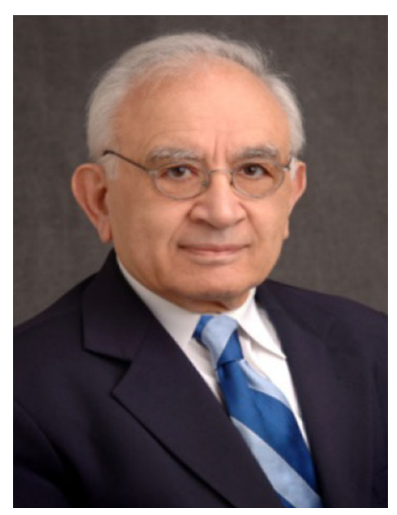

Thomas L. Saaty Chair of Distinguished University Professor, University of Pittsburgh; member National Academy of Engineering; 2012, Herbert Simon Award for best paper in 10 years; 2011 received the distinguished award Doctoris Honoris Causa in a ceremony at Poland's oldest and most prestigious Jagiellonian University, Krakow, Poland; 2008 awarded the Impact Prize by INFORMS for his work on the Analytic Hierarchy Process; 2000; awarded the gold medal from the International Society for Multicriteria Decision Making; 1977 award from the Institute of Management Sciences for one of the best applied studies of that year: The Sudan Transport Plan; 1972 the L.R. Ford prize in mathematics for a comprehensive paper "Thirteen Colorful Variations on Guthrie's Four Color Conjecture". Previously, professor, the Wharton School, University of Pennsylvania; Scientific Analyst at the Arms Control and Disarmament Agency in the Department of State, Washington: nuclear arms reduction negotiations with the Soviets in Geneva. He developed the Analytic Hierarchy Process (AHP) for decision-making and its generalization to feedback, the Analytic Network Process (ANP). Published 43 books and more than 300 papers; latest books Group Decision Making: Drawing out and Reconciling Differences: Problem Solving \& Decision Making; The Brain: Unraveling the Mystery of How It Works; Creative Thinking and Problem Solving; The Neural Network Process (NNP).

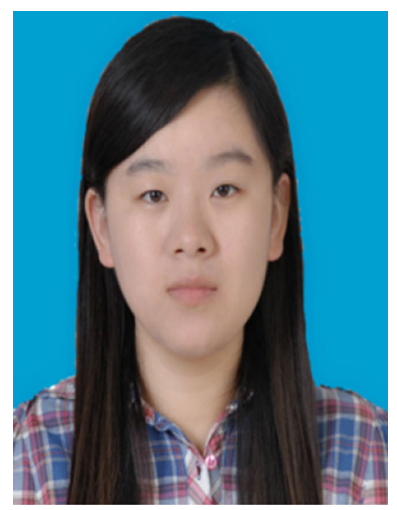

Xiaoyue Liu received a Bachelor degree in Business from Shandong University in 2009. From October, 2013 to October 2014, she visited the Joseph M. Katz Graduate School of Business, the University of Pittsburgh as Ph.D. student of Prof. Thomas L. Saaty. Currently, she is a Ph.D. student at the School of Management and Economics, Beijing Institute of Technology. Her research interests include decision making and emergency management. She has published ten papers about the theory of multi-attribute decision making and its applications.

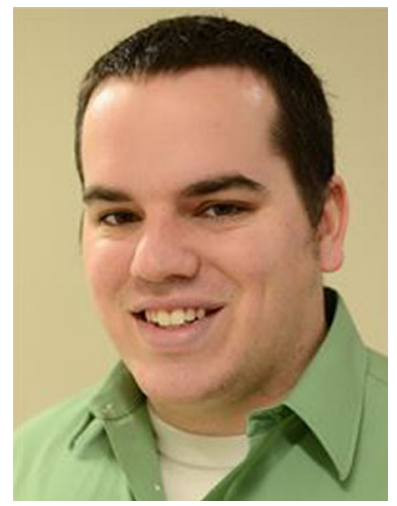

Michael Sanserino received a bachelor of arts in journalism from Indiana University in Bloomington, Ind., in 2009, majoring in journalism and political science. Currently he is a journalist at the Pittsburgh Post-Gazette. His writing subjects include sports marketing, sports analytics, advertising, and energy. Previously, he was a beat writer covering the Pittsburgh Pirates and covered Super Bowl XLV and the 2011 Winter Classic. 